\title{
PESAN DAKWAH DALAM PROGRAM ACARA MUSLIM TRAVELERS NET TV
}

\author{
Dadang Muliawan, Irham Ramdani \\ Komunikasi dan Penyiaran Islam, STID Sirnarasa \\ irhamramdani3838@gmail.com
}

\begin{abstract}
ABSTRAK
Dakwah semakin berkembang dengan adanya Media komunikasi yang terus mengalami kemajuan. Pesan dakwah semakin banyak ragam dan kemasannya. Seperti balnya program acara Muslim Travelers NET TV, yaitu program traveling yang menyajikan pesan dakwah dan dikemas sesuai generasi millennial. Oleh karena itu di dalam penelitian ini mengkeji pesan dakwah pada program acara Muslim Travelers NET TV edisi Kota Jeju Korea Selatan dan pesan dakwah yang dominan. Metode penelitian menggunakan konten analisis yaitu menganalisis dialog atau percakapan dan pesan gambar yang terkandung dalm video tersebut. Hasilnya program acara Muslim Travelers NET TV perjalanan Kota Jeju Korea Selatan mengandung tiga unsur pesan dakwah akidah, akblak dan syari'ah. Pesan akidah tergambarkan dengan ajakan menjaga keimanan, dan menunjukkan keyakinan.
\end{abstract}

Kata Kunci : Dakwah, Program TV, NET TV

\begin{abstract}
$D a^{\prime} w a h$ is increasingly developing with the existence of communication media that continues to progress. Da'wah messages are increasingly varied and packaged. Like the Muslim Travelers NET TV program, which is a travel program that presents da'wah messages and is packaged according to the millennial generation. Therefore, this research examines the message of da'wah in the Muslim Travelers NET TV program in Jeju City, South Korea edition and the dominant dakwah message. The research method uses content analysis, namely analyzing the dialogue or conversation and image messages contained in the video. As a result, the Muslim Travelers NET TV program for the trip to Jeju City, South Korea, contains three elements of the message of da'wah, akidah, morals and syari'ah. The message of faith is illustrated by an invitation to maintain faith, and shows confidence.
\end{abstract}

Keywords: Da'wah, TV Program 


\section{PENDAHULUAN}

Nilai dakwah dalam program televisi menjadi hal penting untuk dikaji. Dakwah menjadi hal yang tidak akan bisa lepas dari umat muslim, Setiap muslim wajib hukumnya meningkatkan iman, salah satunya melalui dakwah, seperti yang dijelaskan Moh. Ali Aziz dalam buku Ilmu Dakwah bahwa dakwah merupakan proses peningkatan iman menurut syari'at Islam. "Proses" menunjukkan kegiatan terus-menerus, berkesinambungan dan bertahap.

Meningkatnya pemahaman agama maka meningkat pula keimanan, kesadaran dan perbuatan. Dimana syariat Islam menjadi tolak ukur dakwah Islam, Al-Qur'an dan Hadits adalah sebagai pijakan utama dalam dakwah. Dalam prosesnya dakwah melibatkan beberapa unsur seperti da'i (orang yang berdakwah), pesan dakwah, metode dakwah, media dakwah, dan mad'u (sasaran dakwah). Dakwah sebagai proses penyampaian ajaran Islam mengajarkan tiga hal seperti yang dijelaskan dalam Hadits (Al-Bukhari : VII : 149), yaitu kesetaraan gender dalam dakwah, kewajiban berdakwah dan pesan dakwah sesuai dengan keadaan penerima dakwah.

Dakwah memiliki ragam bentuk, metode, media, pesan, pelaku, dan mitra (penerima) dakwah. Sehingga pesan dakwah bisa dilakukan oleh siapa saja dan bisa didapat dimana saja. Apapun yang berkaitan dengan Islam, bisa dipastikan ada unsur dakwahnya. Apabila dilihat perkembangan dakwah era modern, dimana teknologi berkembang pesat, dakwah tidak lagi identik dengan mendatangi sebuah majelis. Mad'u bisa mendapatkan pesan dakwah dari mana saja termasuk dari media yang telah berkembang saat ini.

Salah satunya televisi, dengan televisi sebagai alat untuk mempermudah berdakwah, televisi adalah sebuah media telekomunikasi terkenal yang sangat berfungsi sebagai penerima siaran gambar bergerak beserta suara, baik itu yang monokrom (hitam-putih) maupun berwarna. Kata televisi terdiri dari kata tele yang berarti "jarak" dalam bahasa Yunani dan kata visi yang berarti "citra atau gambar" dalam bahasa Latin. Jadi, kata televisi yaitu suatu sistem penyajian gambar berikut suaranya dari satu tempat yang berjarak jauh.( Sutrisno.1993:1).

Menurut Adi Badjuri, televisi adalah media pandang sekaligus media pendengar (audio-visual), yang dimana orang tidak hanya memandang gambar yang ditayangkan televisi, tetapi sekaligus mendengar atau mencerna narasi dari gambar tersebut.(Adi Badjuri, 2010: 39).

Televisi saat ini menjadi salah satu kebutuhan yang sangat penting untuk hiburan. Televisi digunakan sebagai media untuk menyalurkan informasi dengan cepat dan mudah. Televisi sendiri pertama kali ditemukan oleh John Logie Baird yang lahir pada tanggal 13 Agustus 1888 di Skotlandia. Desain Baird yang pertama adalah perangkat elektronik yang disebut dengan nama nipkow disk, lalu disk scanning dikembangkan pada tahun 1884 oleh ilmuwan Paul Nipkow asal Jerman. 
Fungsi alat ini terdiri dari disk karton dengan serangkaian lubang persegi, terletak dalam posisi spiral. Ketika dikombinasikan dengan photoelectriccell dan putaran, nipkow disk mampu men-scan area terang dan gelap dan mengkonversi informasi dari sinyal listrik. Dengan menggunakan seconddisk, dan digabungkan dengan yang pertama, Nipkow mampu mengubah signal ke gambar visual dasar.

Lalu Baird mengolah ide Nipkow, dia mengembangkan sistem dengan sinyal yang bisa dikirim melalui gelombang elektromagnetik nirkabel, Semakin berkembangnya zaman, televisi semakin modern dengan temuan teknologiteknologi canggih.

Televisi sebagai suatu alat dapat dimanfaatkan untuk mengkomunikasikan informasi, dengan menggunakan bayangan gambar dan suara seperti halnya dengan video dan film.( Darwanto Sastro Subroto, Produksi Acara Televisi (Yogyakarta: Duta Wacana University Press, 1994), hlm. 2, Televisi merupakan media yang bisa mempengaruhi khalayak dalam penyampaian informasi. Media televisi sebagai salah satu media massa elektronik yang sangat digemari masyarakat dan memiliki daya tarik karena program audio visualnya mampu memberikan informasi, hiburan, dan pendidikan yang mudah dicerna, dinikmati, dan ditiru.

Sehingga pemirsa televisi sangat cepat dapat dipengaruhi oleh media televisi, baik itu positif ataupun negatifnya Di dalam penyampaian pesan dakwah memang diperlukan media sebagai alat penyampaian untuk dakwah. Media memiliki peran sangat penting, maka pengirim pesan memanglah harus lebih matang dalam mendesain dan merencanakan media apa yang digunakannya, sehingga apabila pesan yang disampaikan efektif dan mampu memberikan efek sesuai yang diinginkan. Media dakwah yang memiliki peran penting dalam kehidupan masyarakat adalah televisi.

Wawan Kuswandi mengatakan "Media televisi mampu menyediakan informasi dan kebutuhan manusia secara keseluruhan. Media televisi menjadi penting bagi manusia untuk memantau kehidupan sosialnya. pemantauan itu bisa dalam bentuk perilaku, mode, bahan sikap terhadap ideologi tertentu. Selain televisi, Adanya internet dan media sosial menjadikan teknologi informasi semakin berkembang. Salah satunya adalah media youtube yang menyampaikan pesan audio visual sama halnya televisi.

Ia menjadi tempat berbagi video yang bisa dijangkau siapapun dan kapanpun. Beberapa stasiun televisi berbagi video program acara mereka ke platform youtube. Sehingga program acara tersebut bisa dinikmati kapanpun, tidak terbatas oleh waktu. Hal tersebut menjadi media dakwah yang bisa dimanfaatkan di era saat ini. Seperti halnya stasiun televisi NET TV merupakan media televisi masa kini, yang salah satu programnya memuat pesan dakwah. Pesan dakwah yang ingin disampaikan kepada mad'u dikemas sesuai dengan generasi anak muda saat ini, yaitu generasi millenials (Manusia yang lahir pada rentang 1980-an hingga 2000). 
Pada program acara tersebut adalah Muslim Travelers (MT), yang menyajikan perjalanan menarik seorang host di berbagai kota di luar negeri. Menyoroti berbagai kehidupan muslim minoritas di berbagai negara belahan dunia. Dalam setiap episodenya host akan berkeliling dan berkunjung ke tempat tempat menarik dan unik seperti situs muslim, komunitas muslim, tempat beribadah, tempat makan halal, tempat bersejarah dimana Islam pernah jaya, tempat berbelanja yang cocok bagi umat muslim, dan bahkan bersilaturahmi kepada para pejuang muslim di tempat tersebut.

Program acara MT ini ada sejak tahun 2014 hingga sekarang tahun 2020. Berbagai negara di Benua Asia dan Benua Eropa menjadi target travelers program ini. Tidak jarang juga program ini mengunjungi tempat tempat sejarah Islam di suatu negara. Seperti tempat bersejarah yang ada di berbagai belahan dunia Muslim Travelers ditayangkan di NET setiap hari pukul 030 WIB selama Ramadhan. Tercatat, MT mendapatkan penghargaan sebagai program Ramadhan terbaik kategori feature/dokumenter dari KPI dan MUI sebanyak enam tahun berturut-turut yaitu dari 2014-2019. Dan pada tahun 2019 MT mendapatkan pernghargaan Kategori Program Wisata Budaya Ramadhan : Muslim Travellers Eps. Jeju Korea Selatan (NET TV).

Begitupun host MT mendapatkan penghargaan kategori host muda inspiratif yaitu Muthia Amalia (Siaran Pers: Penghargaan Program Siaran Anugrah Syiar Ramadhan 2019) Konsep program yang terbilang unik ini menambah beragamnya acara bertemakan keagamaan di televisi saat bulan Ramadhan. MT memiliki berbagai edisi negara yang akan dikunjungi, dan kali ini penulis meneliti tentang perjalanan di negara Korea Selatan.

Perjalanan di Korea Selatan ini yait edisi Potensi wisata muslim di Kota Jeju, Korea Selatan-Muslim Travelers (11 mei 2019), Pada edisi perjalanan negara Korea Selatan ini sangat menarik untuk diteliti pesan dakwahnya, karena Islam di negara minoritas muslim tetapi muslim warganya sangat antusias menjalankan ibadah menjalin silaturahmi antar umat muslim di daerah di Korea Selatan, mengunjungi restoran hahal, dan mengunjungi masjid pertama di daerah Jeju Korea Selatan. Sehingga memunculkan beberapa pertanyaan: (a) Apa saja pesan dakwah verbal yang di sampaikan dalam program acara Muslim Travelers NET TV edisi Kota Jeju Korea Selatan ?. (b) Apa saja pesan dakwah non-verbal dalam program acara Muslim Travelers NET TV Edisi Kota Jeju Korea Selatan ?. Metode yang digunakan dalam penelitian ini adalah kajian yang bersifat konten analisis, yaitu dengan cara mencatat nilai-nilai isi kandungan pesan dakwah dalam adegan atau dialog di dalam Video Program Cara Muslim Traveles Net Tv Edisi Jeju Korea Selatan.

\section{LANDASAN TEORITIS}


Pesan dakwah harus berisi kebenaran. Hal yang membedakan pesan dakwah dengan pesan komunikasi lainya adalah sumber pesan yang disampaikan. Pesan dakwah harus bersumber dari Al-Qur'an dan Hadits. Semua ayat yang ada dalam Al-Qur'an adalah firman Allah SWT. Ayat-ayat itu diturunkan kepada Nabi Muhammad SAW lalu Nabi membacahkan kepada para sahabatnya.

Untuk bisa melaksanakan segala sesuatu yang di wahyukan Allah SWT, umat muslim diperintahkan mengikuti apa yang diucapkan dan dilakukan oleh Nabi Muhammad, hal ini disebut dengan Hadits. Seluruh ayat Alqur'an dan teks Hadits adalah pesan dakwah. Disamping itu, beberapa pola dakwah juga banyak dijelaskan dalam Al-Qur'an dan Hadits. Al-Qur'an dan Hadits tidak bisa dipisahkan sebagai sumber pesan dakwah. Karena kebenaran wahyu memerlukan kebenaran Akal. (Moh. Ali Aziz, 2015:143).

Pedan dakwah meliputi berbagai aspek kehidupan, banyak sekali ragamnya, sehingga para cendikiawan muslim menggenaralisir ada bebebrapa kajian penting dalam pesan dakwah, diantaranya: kajian akidah, kajian ini erat kaitanya dengan keyakinan manusia terhadapa tuhannya seperti yang dismapaikan oleh Hammis yang menyatakan keyakinan yang kokoh dihati, bersifat mengikat dan mengandung perjanjian keyakinan yang kokoh dihati, bersifat mengikat dan mengandung perjanjian.

Selanjutnya kajian dakwah yaitu mengenai syariah, Syari'ah dalam konteks kajian hukum Islam lebih menggambarkan kumpulan norma-norma hukum yang merupakan hasil dari proses tasyri'. Tasyri' adalah menciptakan dan menerapkan Syari'ah. Dalam kajian hukum Islam tasyri' sering didefinisikan sebagai penetapan norma-norma huku $\mathrm{m}$ untuk menata kehidupan manusia, baik dalam hubungannya dengan tuhan maupun dengan umat manusia lainnya. (Hammis Syafaq dkk, 2014:32). Ajaran akhlak dalam Islam pada dasarnya meliputi kualitas perbuatan manusia yang merupakan ekspresi dari kondisi kejiwaannya. Sehingga materi akhlak dalam Islam menngenai sifat dan kriteria perbuatan manusia serta berbagai kewajiban yang harus dipenuhi. (M. Munir dan Wahyu Illaihi:2015:29), Menurut M. Munir dan Wahyu ilaihi yang mengutip Abdul Aziz Dahlan menjelaskan bahwa Materi akhlak ini diorientasikan untuk dapat menentukan baik dan buruk, akal, dan kalbu berupaya untuk menemukan standar umum melalui kebiasaan masyarakat.

Karena ibadah dalam Islam sangat erat kaitanya dengan akhlak. Ibadah dalam Al-Qur'an selalu dikaitkan dengan taqwa, berarti melaksanakan apa yang diperintah Allah dan menjauhi apa yang dilarangNya. (M. Munir dan Wahyu Illaihi,2015:31).

media dakwah merupakan alat atau sarana yang digunakan untuk menyalurkan pesan dakwah yang sesuai dengan Al-Qur'an dan Al-Hadits. Seperti halnya yang dikatakan M. Munir dan wahyu Ilaihi dalam bukunya bahwa media dakwah merupakan alat yang digunakan sebagai sarana menyampaikan pesan 
dakwah ajaran Islam kepada mad'u. (M. Munir dan Wahyu Illaihi, Managemen Dakwah, (Jakarta: Kencana, 2015), h 32, Sedangkan Menurut Moh. Ali Aziz definisi media dakwah adalah alat yang menjadi perantara penyampaian pesan dakwah kepada mitra dakwah, ia menegaskan bahwa media dakwah ini sanngat berbeda dengan metode dakwah dan logistik dakwah. (Moh. Ali Aziz, 2015: 404405).

Oleh karena itu eksistensi dan urgensi media menjadi sangat penting bagi dakwah dalam menopang budaya dan peradapan manusia. Sehingga media dakwah di bagi menjadi bermacam-macam bentuknya. Hamzah Ya'qub didalam buku komunikasi dakwah yang ditulis Wahyu Ilaihi dkk. ini membagi media dakwah menjadi lima macam yaitu : (Wahyu Ilaihi, Lukman Hakim dkk,2013:40). (a)Lisan, media lisan ini menjadi media yanng sangat sederhana dengan menggunakan lidah dan suara. Media ini bisa berbentuk pidato, ceramah, kajian, kuliah, dan lain sebagainya. (b)Tulisan, media ini bisa berupa bentuk apapun yang terdapat tulisan didalamnya, misalkan majalah, surat kabar, banner, spanduk dll. (c) Lukisan, media ini hanya berbentuk visual saja yaitu berupa gambar, karikatur, dan lain sebagainya. (d) Audio visual, media ini banyak digunakan diera sekarang ini, perpaduan antara lisan atau audio dan visual atau gambar. Alat dakwah ini bisa merangsang indera pendengaran atau penglihatan dan kedua-duanya. Media ini berbentuk video, televisi, slide, bahkan media baru saat ini juga mengunakan media audio visual.

video merupakan salah satu media dakwah yang memiliki kemampuan mempengaruhi yang begitu besar. Karena video memainkan dua indra dari komunikan (orang yang menerima pesan), audio visual yang mana indra penglihatan dan pendengaran digunakan dalam mengelola pesan dakwah yang disampaikan. Dalam Al-Qur'an indra penglihatan dan pendengaran diberikan Allah kepada manusia agar bisa menerima dan memahami pesan yang diberikan lingkungan sekitar dengan baik.

Pesan dakwah melalui video banyak dijumpai diberbagai macam media diantaranya: pertama Media Lama. Media lama merupakan media yang terikat oleh waktu, dimana pesan yang disampaikan hanya bisa dinikmati pada waktu yang telah ditentukan dan khalayak tidak bisa terhubung pada media maupun sesama pengguna. Misalkan VCR (Video Cassette Recorder), DVD (Digital Video Disc) , Mobile Video, DVR (Digital Video Recorder), Video Game, Film dan Televisi.

Kedua Media baru, Media baru atau yang disebut dengan new media ini merupakan media komunikasi yang memungkinkan adanya interaksi antara pemberi pesan dengan penerima pesan, dan media baru ini bisa diakses kapan dan dimana aja melalui berbagai macam perangkat digital.( Bruno Schivinski dan Dariusz Dabrowski, 2014:2-19).

Adanya perkembangan informasi dan digitalisasi yang semakin cepat, menjadikan media lama menggikuti media baru. VCR, DVD, Mobile Video, 
Video Game, Film dan Televisi sekarang ini bisadidapatkan melalui media baru. Media baru banyak digunakan beberapa stasiun televisi untuk mengikuti era digital, dan media baru ini memiliki keunggulan dalam hal digitalisasi. Hal ini juga menjadi hal baru dalam menyampaikan pesan dakwah video melalui media baru. Media Baru yang berkembang saaat ini diantaranya: (a) Website atau situs Online, tempat menyediakan berbagai macam ragam pesan didalamnya. Diantaranya layanan berita online, streaming film, dan layanan streaming televisi. Tidak jarang juga situs online juga menyediakan dalam bentuk aplikasi mobile. (b) Media sosial, merupakan platform sosial yang memungkinkan pengguna dengan leluasa mengirim informasi pribadi maupun publik. Diantaranya facebook, instagram, twitter, dan lain sebagainya. (c) Youtube, merupakan platform yang memungkinkan pengguna bisa mengunggah video dan menikmati video diseluruh dunia.

Video memiliki bermacam-macam komunikasi, karena video memiliki sifat audio visual, secara garis besar dapat dibagi menjadi dua, diantaranya: pertama Pesan Verbal Pesan verbal menurut Deddy Mulyana adalah semua jenis simbol yang menggunakan satu kata atau lebih dengan usaha-usaha yang dilakukan secara sadar untuk berhubungan dengan orang lain secara lisan. Sistem kode verbal yang digunakan disebut bahasa, yang mana bahasa adalah seperangkat simbol, dengan aturan untuk mengombinasikan simbol-simbol tersebut, yang digunakan dan difahami suatu komunitas. (Deddy Mulyana, 2010: 260).

Dalam Al-Qur'an ada tiga istilah pesan verbal, diantaranya lafdz, qaul, dan kalimat. Lafdz berarti melempar, dimana bunyi yang keluar dari mulut ibarat bunyi atau simbol yang dilemparkan dari mulut. Qaul berarti kata yang diucapkan oleh lisan baik maknanya sempurna atau tidak. Dan kalimat dalam bahasa arab berarti senyawa dari dua unsur yaitu lafdz dan ifada, dimana kalimat lebih luas cakupanya daripada qaul. (Harjani Hefni, Komunikasi Islam, (Jakarta: Kencana, 2017), hh 79-100)Pesan verbal dalam video ini terlihat dari pengunaan bahasa yang digunakan. Baik berupa ucapan yang dikirm melalui suara, maupun tulisan yang ditampilkan sebagai subtitle. Maupun tulisan berupa kutipan ayat Al-Qur'an.

Kedua Pesan Non-verbal Pesan non-verbal menurut Deddy Mulyana dengan mengutip Larry A. Samovar, menyatakan bahwa pesan non-verbal adalah semua isyarat yang bukan kata-kata. Mencakup semua rangsangan (kecuali rangsangan verbal) dalam suatu setting komunikasi, yang dihasilkan oleh individu dan penggunaan lingkungan oleh individu, yang mempunyai nilai pesan potensial bagi pengirim atau penerima. (Deddy Mulyana, 343).

Dalam Al-Qur'an pesan non-verbal banyak dijelaskan melalui makna isyarat mata, wajah, tangan, kaki, gerakan tubuh, bibir, kepala dan seterusnya. Meliputi isyarat dari ujung kepala sampai ujunng kaki. (Harjani Hefni, 2017:79110) Albert Mehrabian mengatakan bahwa orang dapat berkomunikasi melalui berbagai saluran komunikasi non-verbal dan bukan hanya sekedar kata-kata yang 
diucapkan. Albert membagi komunikasi non-verbal atau perilaku kinetik yang interaktif menjadi beberapa kategori, diantaranya: (a) Jarak pandang antar pribadi. (b) Arah pegangan. (c) Sandaran tubuh atau orientasi tubuh. (d) kspresi wajah (e) Pandangan mata yang melebar untuk menghalau hambatan tertentu. (f) Gerakan tangan. (g) Gerakan kaki atau telapak kaki. (h) Perilaku membelai. (i) Gerakan melalui manipulasi self maupun manipulasi objek. (j) Penyesuaian postur tubuh.

Oleh karena itu pesan non-verbal dalam video bisa ditemukan oleh banyak hal, melalui berbagai macam isyarat, peraga dan berbagai bentuk gerakan atau perilaku kinetik.

\section{HASIL DAN PEMBAHASAN}

NET adalah bagian dari kelompok usaha INDIKA GROUP, Grup ini bergerak di bidang usaha Energi \& Sumber daya di bawah bendera Indika Energy Tbk. (www.indikaenergy.com), INDIKA berdiri dengan visi untuk membangun usaha di bidang Media Hiburan dan Teknologi Informasi, Nama INDIKA sendiri merupakan singkatan dari Industri Multimedia dan Informatika. Saat ini, melalui PT. Indika Multimedia, INDIKA GROUP bergerak di bidang usaha Promotor, Broadcast Equipment, Production House dan Radio, Netmediatama (http://www.netmedia.co.id/ aboutdiaksestanggal 25 Maret 2019).

Muslim Travelers merupakan salah satu program NET khusus di bulan Ramadhan. Muslim Travelers ini menyajihkan berbagai info traveling, khususnya bagi travelers muslim. Program ini memberikan nuansa Islam dengan kemasan yang menarik untuk memperkaya hari-hari dibulan ramadhan. Muslim Travelers dipandu oleh host yang mengunjungi beberapa muslim yang tinggal di kota tujuan. Mengelilingi berbagai kota tujuan, mulai dari berbagai tempat menarik untuk dikunjungi, tempat dimana terpancar cahaya Islam, berbagai tempat kuliner yang menyajikan menu makanan halal, dan tentunya mengeksplor tempat bagi para muslim menjalankan ibadah

\section{Pesan Dakwah Verbal Dalam Video Program "Muslim Travelers Net Tv Edisi Kota Jeju Korea Selatan"}

Host Muslim Travelers membuka acara dengan mengagungkan Allah SWT. Menit : 00:15 sampai 00:29. Sesungguhnya Allah menunjukan tanda tanda kebesarannya melalui apa yang ia ciptakan di langit dan di bumi agar kita sebagai manusia beriman serta mensyukuri karunia yang ia berikan. Pesan di atas mengandung pesan dakwah Akidah, pesan yang mengajak kita lebih beriman kepada Allah dengan mengetahui kebesaran Allah atas apa yang di ciptakannya, dengan bertambahnya iman kita akan lebih mensyukurinya atas apa yang Allah berikan kepada kita, menyampaikan pesan dakwah melalui suara, opening tayangan dengan meyakinkan bahwa Allah maha besar. 
Muthia memulai acara dengan mengucap salam epada pemirsa. Menit 02:50 sampai 02:53. "assalamualaikum selamat datang di Jeju "Pesan ini menunjukan pesan dakwah kategori Akhlak, dengan memulai tayanngan dengan mengucapkan salam kepada pemirsa, mengucap salam adalah akhlak yang baik yang wajib bagi umat muslim, hal itu tertulis dalam Al Quran dalam beberapa ayat yang menganjurkan mengucapkan salam. Baik saat masuk rumah maupun saat bertemu kerabat, "wahai orang orang yang beriman! janganlah kalian memasuki rumahh yang bukan rumah kalian sebelum meminta ijin dan dan memberi salam kepada penghuninya". (QS. An-Nur ayat 27).

Selaih hal itu, para kru dan host juga melakukan berdo'a besama. Pesan di atas menunjukan kategori pesan dakwah syari'ah, host program muslim travelers mengutarakan pentingnya berdoa terlebih dahulu untuk mecari nafkah agar selama mencari nafkah di berikan keselamatan, berdoa adalah syari'at yang Allah anjurkan kepada seluruh hambanya, doa adlah senjatanya umat muslim, sebelum kita melakun aktivitas apapun sebaiknya berdoa terlebih dahulu, seperti sabda Rasululloh "Berdoalah kepada Allah dalam keadaan yakin akan di kabulkan, dan ketahuilah bahwa Allah tidak mengabulkan doa dari hati yang lalai." (HR. Tirmidzi). pesan dakwah lainnya kategori akhlak, Muthia bertamu kepada temannya yang sedang berada di Korea Selatan, ketika bertemu mengucapkan salam kepada sakinah, dan saling sapa keduanya, sakinah pun mengajak masuk ke dalam rumahnya, bertamu kepada teman, menjalin silaturahmi mendapat berbagai manfaat, dilapangkan rizki dan umur panjang, sepeti sabda Rasululloh "siapa saja yang senang di beri lebih banyak kemakmuran dan umur panjang, maka dia harus menjalin hubungan baik dengan orangtu dan saudaranya." (HR Bukhari).

\section{Pesan Dakwah Non-Verbal Dalam Video Program "Muslim Travelers Net Tv Edisi Kota Jeju Korea Selatan"}

Gambar 1. Menyapa dengan senyuman

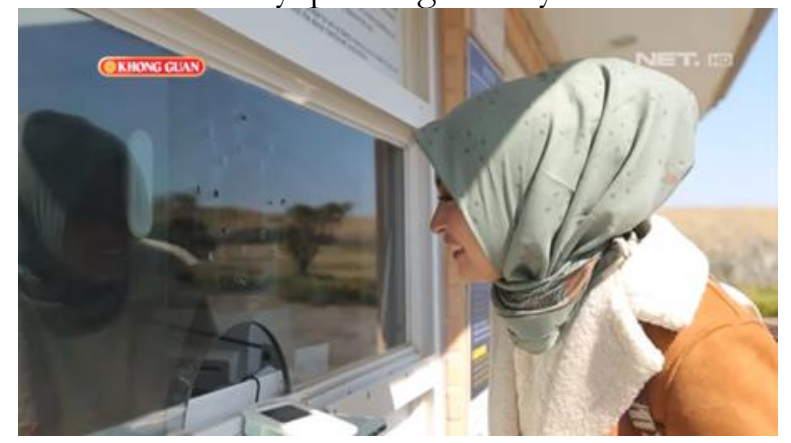

Gambar di atas menunjukan pesan dakwah kategori akhlak, menyapa sambil tersenyum kepada orang lain ialah akhlak terpuji yang senantiasa harus kita biasakan dalam kehidupan sehari hari, menyapa dengan tersenyum bisa membuat orang lain bahagia itu sedekah, membuat orang bahagi itu ibadah, akhlak terpuji, 
Rasululloh bersabda "senyumanmu di hadapan saudaramu adalah sedekah bagimu.” (HR Tirmidzi).

Gambar 2 Interkasi dengan penyelam tradisional

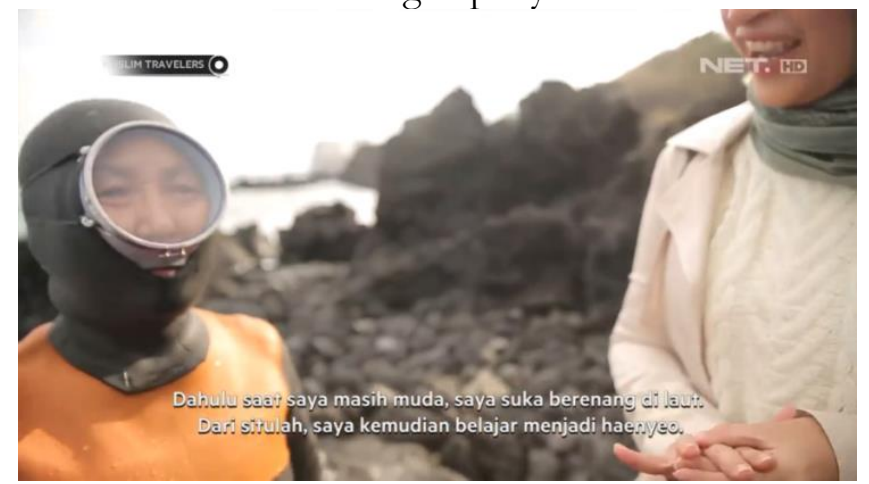

Pesan dakwah gambar di atas menunjukan pesan dakwah kategori akhlak, sebagi mahluk social kita perlu senantiasa berkomunikasi dengan orang lain, entah secara langsung maupun menggunakan media komunikasi, menjalin komunikasi dengan baik adalah sebuah kabikan dengan menerepka etika dalam berkomunikasi dengan lawan bicara, banyak manfaat yang terdapat saat kita berinteraksi dengan orang lain dapat menambah wawasan dan ilmu pengetahuan, melalui komunikasi nantinya akan terjadi transfer ilmu antara pihak satu dengan pihak lain.

Gambar 3 Berinteraksi dengan bahasa tubuh

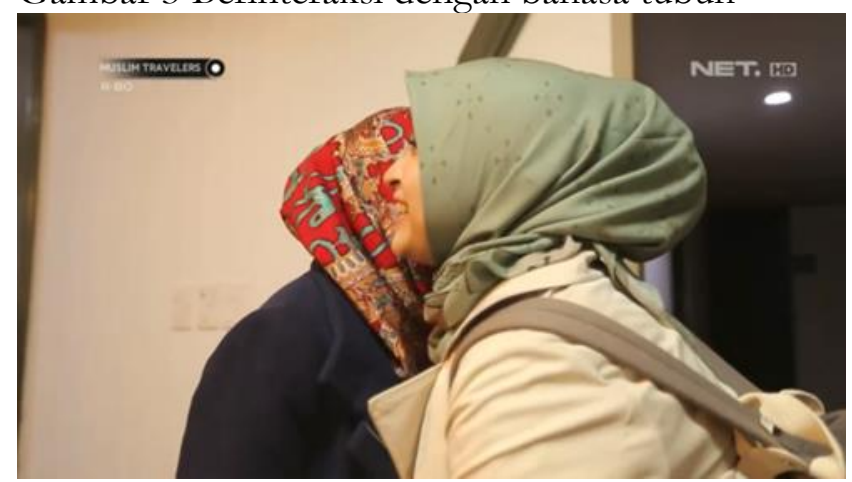

Pesan dakwah yang terdapat pada gambar di atas yaitu pesan dakwah kategori akhlak, Muthia bertamu ke rumah kediaman sakinah yang sudah lama tidak bertemu, bertamu dan berinterksi dengan bahasa tubuh ini adalah perilaku baik yang di contohkan oleh para sahabat nabi yang biasa di sebut al-mu'anaqoh, selain itu al-mu'anaqoh sering di lakukan oleh para ulama, kiai dan santri, menurut Imam nawawi hukum al-mu'anaqoh itu sunah jika di lakukan oleh mereka yang baru pulang dari perjalanan yang jauh, antara dua orang yang lama tidak bertemu, atau bertemu anak kecil.

Gambar 4 Wawancara dengan Narasumber 


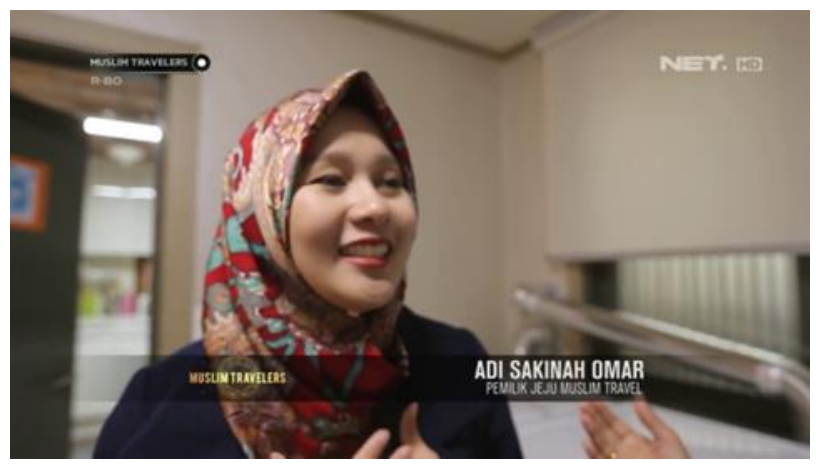

Pesan dakwah yang terkandung dalam gambar di atas yaitu pesan dakwah akhlak, mewawancarai narasumber untuk mencari informasi dan menambah ilmu baru, serta kerkomunikasi dengan teman dengan tatakrama yang baik adalah perilaku baik, mewawancarai pengalaman melayani dan membantu para wisatawan muslim yang sering membutuhkan travel yang ramah bagi umat muslim.

Gambar 5 Interaksi dengan Adi Sakinah Omar saat berjalan

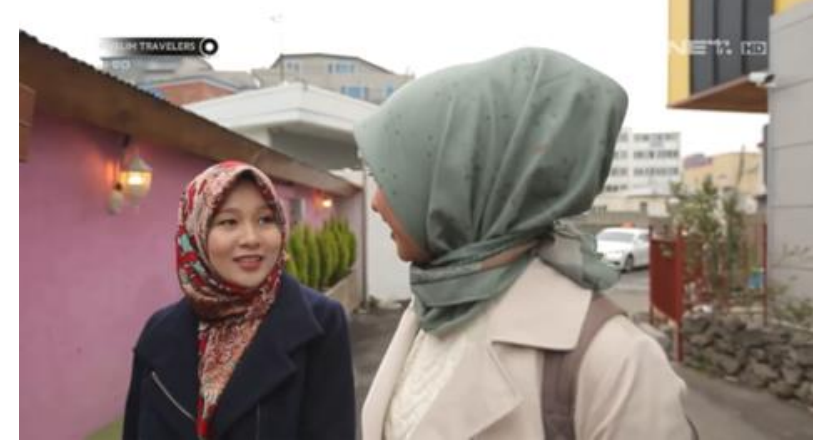

Pesan dakwah yang terdapat pada gambar di atas menunjukan pesan dakwah kategori akhlak, interaksi menjalin keakraban menjaga keeratan dalam pertemana adalah perilaku baik, menjaga silaturahmu dengan terus berkomunikasi walau saat sedang berjalan, dengan komunikasi seseorang dapat pengetahuan yang luas serta menambah teman.

Gambar 6 Bertamu dan interaksi memperlihatkan tempat menginap yang ramah muslim.

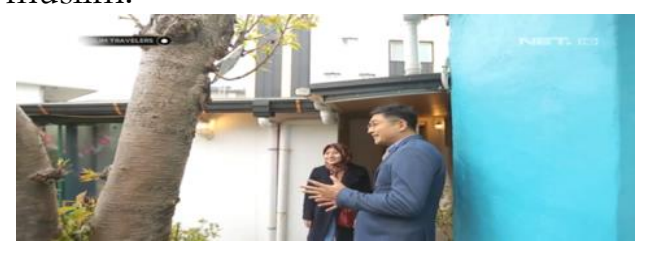

Pesan dakwah yang terdapat pada gambar di atas menunjukan pesan dakwah kategori akhlak, bertamu ke tempat penginapan yang ramah muslim, dan 
berbincang seputar pasilitas yang umat muslim perlukan saat menginap, bertamu dan bersilaturahmi adalah kebaikan, selain mempererat tali silaturahmi pengunjung juga bisa menambah wawasan ilmu.

\section{Gambar 7 Menyapa saat bertamu}

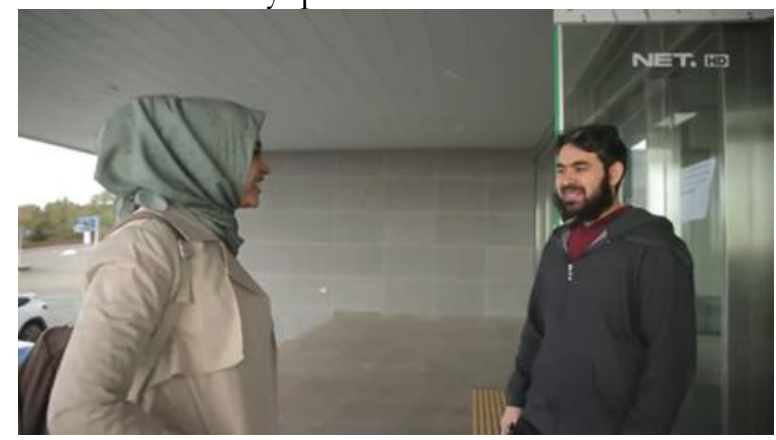

Pesan dakwah yang terdapat pada gambar di atas menunjukan pesan dakwah kategori akhlak, bertamu ke tempat komunitas muslim di Korea Selatan, menjalin persaudaraan dengan mahasiswa muslim perilaku yang baik, di dalam islam Rasululloh sering menganjurka sering kali menyuruh umat islam untuk saling bersatu agar tidak bercerai berai, tentu efek silaturahmi kekuatan umat islam bisa bersatu dan saling bahu membahu.

Gambar 8 Mahasiswa sedang membaca buku

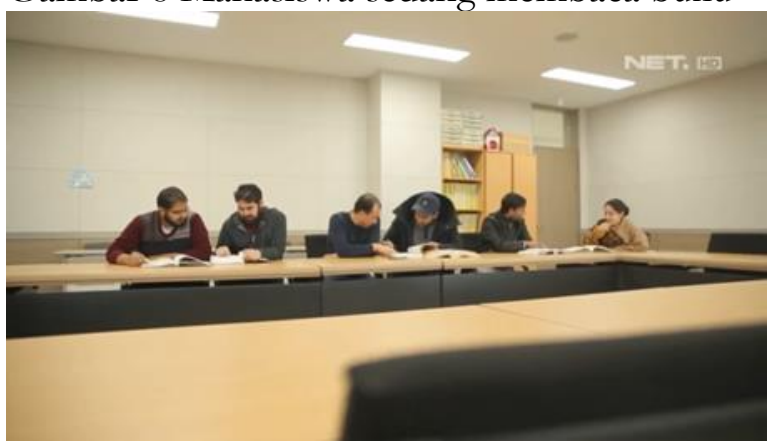

Pesan dakwah yang terdapat pada gambar di atas menunjukan pesan dakwah kategori akhlak, buku adalah jendela dunia dan kegiatan membaca buku merupakn suatu cara untuk membuka jendela tersebut agar kita bisa mengetahui lebih tentang dunia yang belum kita ketahui sebelumnya, buku merupakan sumber informasi yang dapat membuka wawasan tentang berbagai hal, dan mecari ilmu adalah akhlak baik yang di wajibkan untuk umat muslim.

Gambar 9 Mahasiswa sedang mendengarkan tausiah 


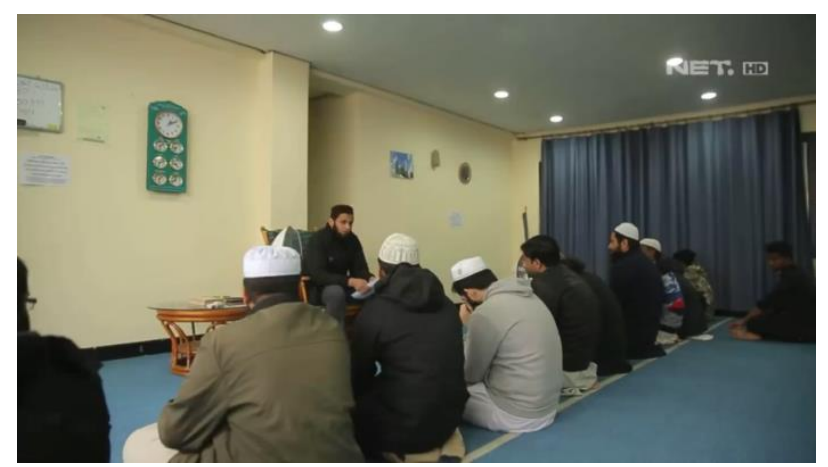

Pesan dakwah yang terdapat pada gambar di atas menunjukan pesan dakwah kategori akhlak, datang ke tempat pengajian tenteng ilmu agama dalah perilaku baik yang di wajibkan bagi seluruh umat muslim, Rasululloh menkankan keutamaan menuntut ilmu baik ilmu pengetahuan umum serta ilmu agama, ilmu agama dalah bekal hidup di dunia agar senantiasa berada di jalan Allah SWT. Orang yang keluar dari rumahnya menuju masjid untuk menuntut ilmu syar'i, maka ia sedang menempuh jalan menuntut ilmu, Rasululloh bersabda "Barangsiapa menempuh jalan menuntut ilmu, maka Allah akan memudahkan jalannya untuk menuju surga" (HR. At Tirmidzi).

Gambar 10 Saat mewawancarai

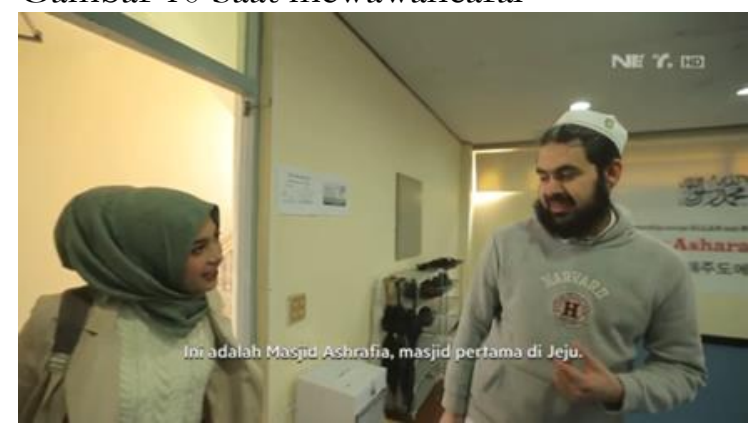

Pesan dakwah yang terdapat pada gambar di atas menunjukan pesan dakwah kategori akhlak, bertamu menjalin silaturahmi dan mencari tau dengan mewawancarai narasuber untuk menambah wawasan ilmu penegtahuan adalah perilaku baik, mencari tahu bagai mana perkembangan muslim di kota Jeju dan perjuangan saat membangun masjid bersama mahasiswa muslim yang ada di Korea Selatan.

Gambar 11 Seseorang sedang membaca Al Quran 


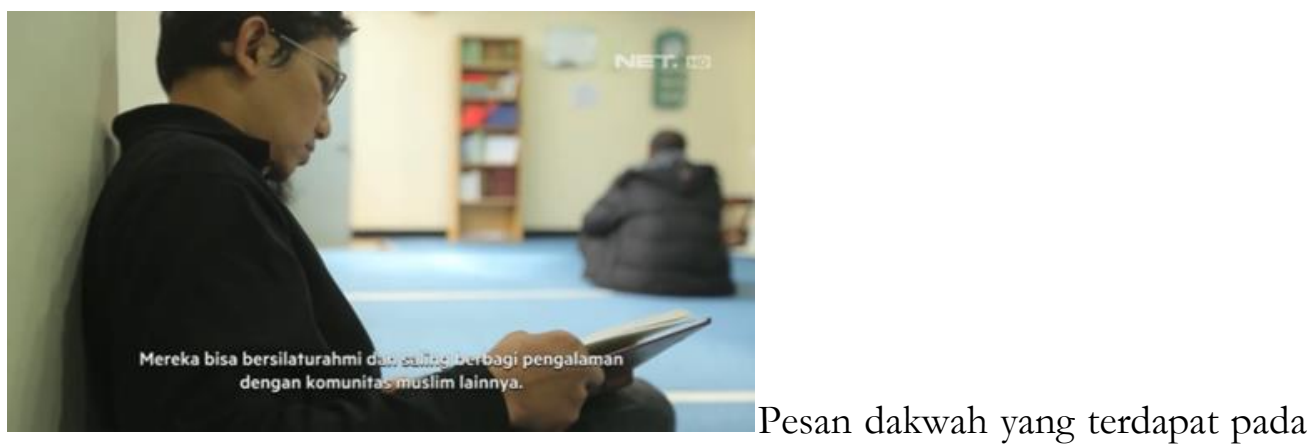

gambar di atas menunjukan pesan dakwah kategori ayari'ah, membaca quran adalah ibadah yang di wajibkan bagi umat muslim, Membaca Al-Qur’ân merupakan langkah awal seseorang bermuamalah dengan Al-Qur’ân. Nabi Shallallahu 'alaihi wa sallam memerintahkan agar kita rajin membacanya, sebagaimana tertuang dalam sabda beliau Shallallahu 'alaihi wa sallam. Bacalah AlQur`ân, karena ia akan datang pada hari Kiamat sebagai pemberi syafaat bagi orang yang membacanya (HR Muslim) Allah menjadikan amalan membaca AlQuran termasuk sebagai salah satu yang bernilai ibadah kepada-Nya. Allah memberikan pahala bacaan Al-Quran bukan per surat atau per ayat, akan tetapi pahalanya per huruf dari Al-Quran yang kita baca.

Gambar 12 Seorang mahasiswa sedang Adzan

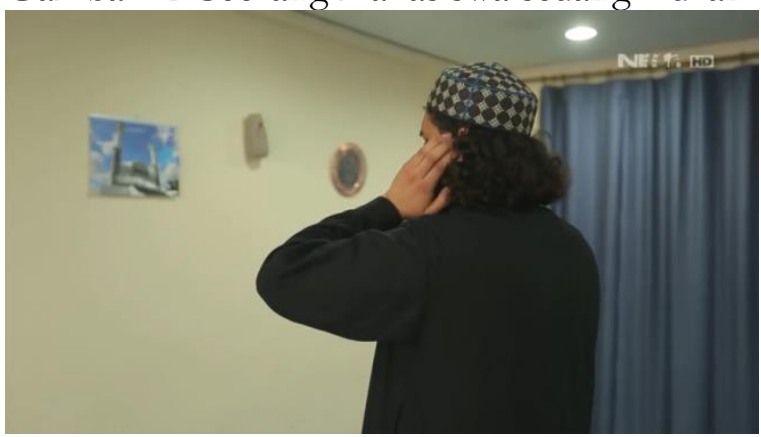

Pesan dakwah yang terdapat pada gambar di atas menunjukan pesan dakwah kategori syari'ah, yang berhubungan dengan peribadahan kepada Allah, Saat akan memasuki waktu shalat, umat muslim di penjuru dunia pasti akan mendengarkan suara adzan berkumandang dan bersahut-sahutan dari masjid satu dengan masjid lainnya. Adzan merupakan seruan untuk seluruh umat muslim sebagai tanda masuknya waktu shalat fardhu seperti subuh, dzuhur, ashar, maghrib, dan isya. Ketika sudah mendengar suara adzan, hendaknya setiap muslim segera bergegas untuk mengambil air wudhu dan bersiap shalat berjamaah maupun sendirian.

Gambar 13 Ketika melaksanakan shalat berjamaah 


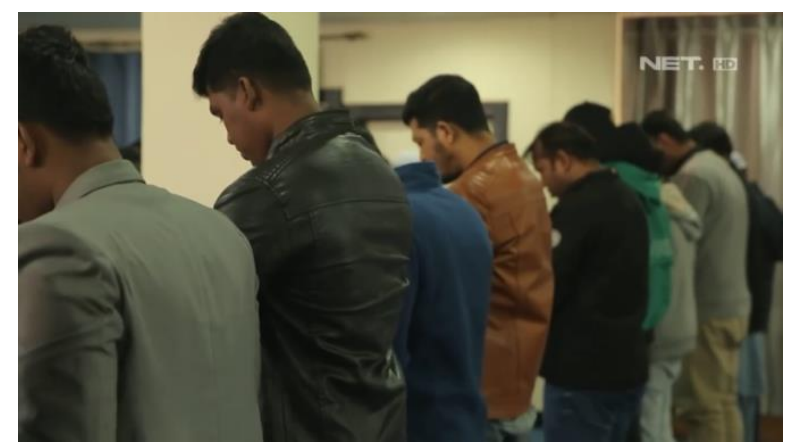

Pesan dakwah yang terdapat pada gambar di atas menunjukan pesan dakwah kategori ayari'ah, shalat merupakan ibadah yang wajib di laksanakan bagi seluruh umat muslim, mahasiswa Korea Selatan ini selalu menjaga waktu shalat berjamaah, Shalat memberikan banyak manfaat bagi yang istiqamah menjalankannya. Selain itu, shalat memiliki banyak keutamaan, apalagi jika ditunaikan berjamaah. Satu hal yang perlu diketahui, tidak satu pun ulama yang menyatakan shalat berjamaah hukumnya sunah biasa, Shalat berjamaah adalah sunah muakkadah bagi laki-laki dalam menjalankan shalat lima waktu. Menurut Mazhab Maliki dan Hambali, hukumnya wajib, Rasulullah bersabda, "Demi Tuhan yang jiwaku berada dalam kekuasaan-Nya. Sungguh aku sangat ingin menyuruh orang-orang mengumpulkan kayu bakar, lalu menyuruh seseorang supaya menyerukan azan, kemudian menyuruh seseorang pula untuk menjadi imam bagi orang banyak. Sementara itu, aku akan pergi mendatangi orang-orang yang tidak shalat berjamaah, lalu aku bakar rumah-rumah mereka." (HR Bukhari Muslim).

Gambar 14 Ketika selesai shalat berjamaah dan pamit bersalaman

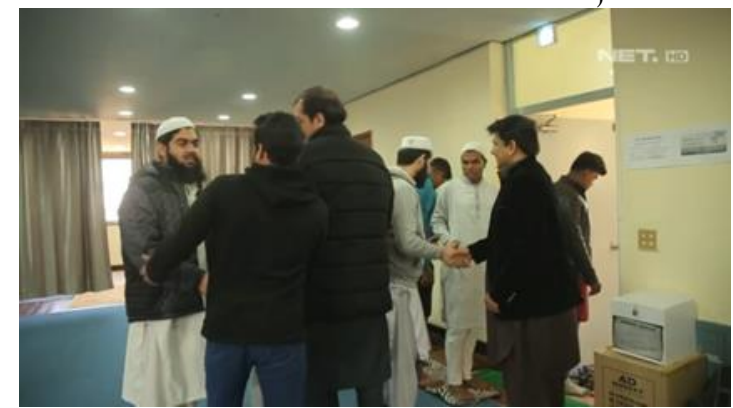

Pesan dakwah yang terdapat pada gambar di atas menunjukan pesan dakwah kategori akhlak, berjabat tangan adalah budi pekerti yang baik, mahasiswa Korea menunjukan berjabat tangan saat selasai melaksanakan shalat berjamaah, Berjabat tangan adalah ibadah yang disyari'atkan ketika bertemu dan berpisah, maka melakukannya di selain kedua waktu tersebut, misalnya setelah shalat lima waktu.

Gambar 15 Berkunjung ke pemilik restoran halal 


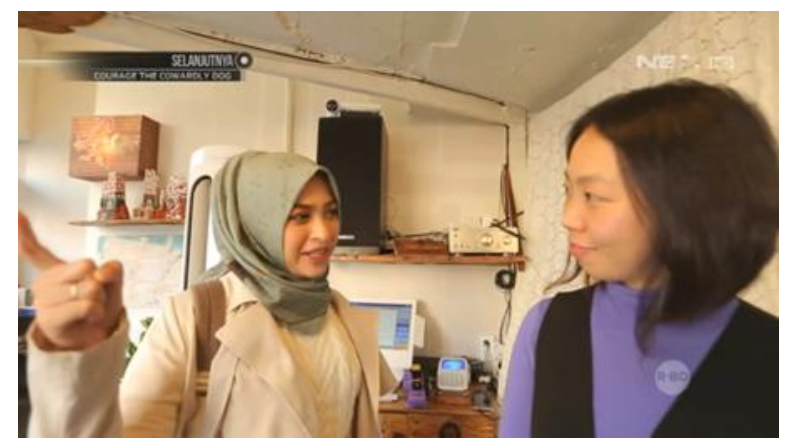

Pesan dakwah yang terdapat pada gambar di atas menunjukan pesan dakwah kategori akhlak, berkunjung atau bertamu denga nejalin tali silaturahmi adalah perilaku naik, Muthia berkunjung ke tempat restoran halal di kota Jeju dan berinteraksi denganpemilik restoran.

Gambar 16 Melayani Pengunjung

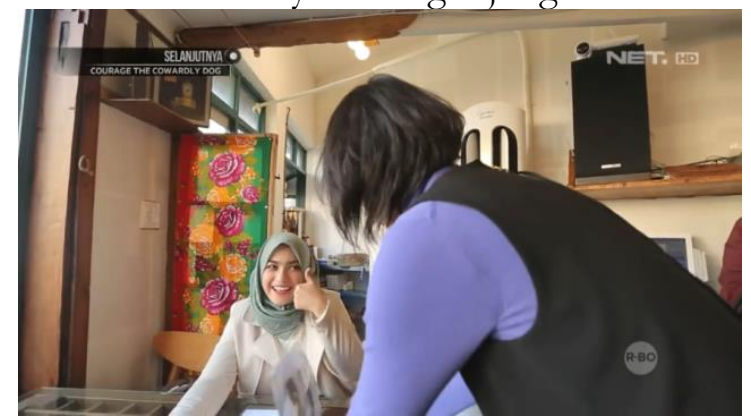

Pesan dakwah yang terdapat pada gambar di atas menunjukan pesan dakwah kategori akhlak, pemilik restoran melayani dengan penuh simpati kepada Muthia, mekipun dia pemilik restoran, tetapi ia rela malayani temannya yang berkunjung ke tempatnya, ini merupakan budi pekerti yang baik, yang mesti kita tiru kebaikannya. Begitu dahsyatnya memuliakan tamu. Sebagaimana disebutkan dalam sebuah Hadits, memuliakan tamu itu ganjaran pahalanya sama dengan pahala seperti melakukan ibadah haji dan umrah. Tentu rasanya tidak ada seorang muslim pun yang menolak memuliakan tamu jika ia mengetahu pahalanya yang begitu besar, Dari Ibnu Abas Radhiyallahu'anh Nabi Shallallahu 'Alaihi Wasallam bersabda, "Jika ada tamu masuk ke dalam rumah seorang mukmin, maka akan masuk bersama tamu itu seribu berkah dan seribu rahmat. Allah akan menulis untuk pemilik rumah itu pada setiap kali suap makanan yang dimakan tamu seperti pahala haji dan umrah".

Gambar 17 Mewawancarai pemilik restoran halal 


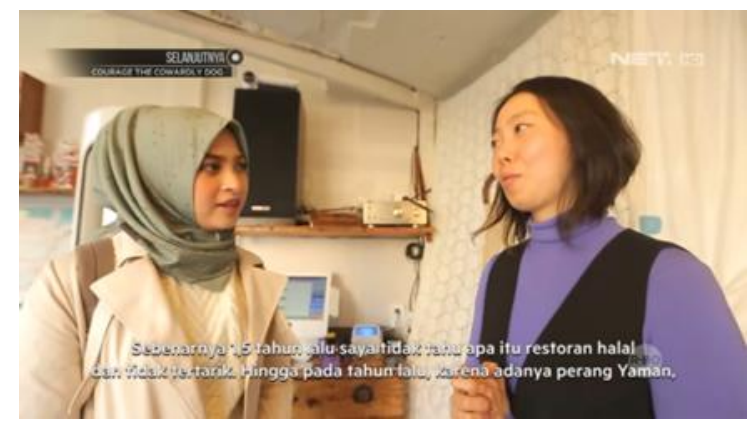

Pesan dakwah yang terdapat pada gambar di atas menunjukan pesan dakwah kategori akhlak, silaturahmi sambil berbincang dan bertukar pikiran adalah perilaku yang baik, Muthia mewawancarai pemilik restoran halal, menjelaskan senang membantu para warga muslim lokal maupun wisatawan untuk lebih mudah membeli makanan yang halal, Dengan kata lain, banyak hal yang bisa kita raih untuk mendapatkan keutamaan di sisi Allah dengan menumbuhkan semangat membantu sesama. Seperti memberi kemudahan dan kenyamanan saat makan makanan yang terjamin kehalalannya, Demikianlah kedudukan amal membantu sesama di dalam Islam. Rasulullah bersabda, "Siapa yang ingin diselamatkan oleh Allah dari kesulitan pada Hari Kiamat, hendaklah ia memberikan kemudahan kepada orang yang kesulitan" (HR. Muslim).

Gambar 18 Saat makan dengan tangan kanan

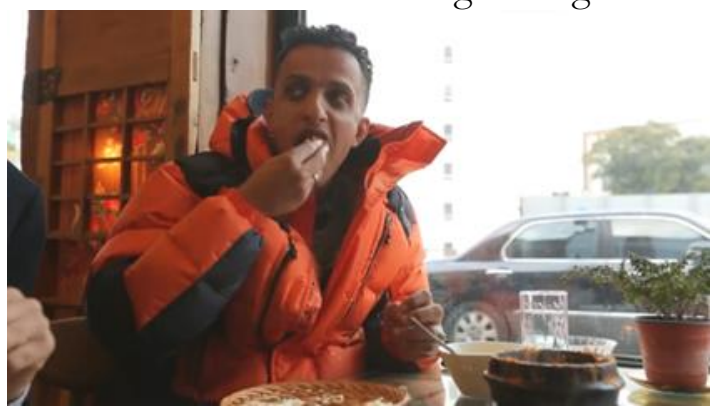

Pesan dakwah yang terdapat pada gambar di atas menunjukan pesan dakwah kategori akhlak, membiasakan makan dengan tangan kanan adalah akhlak yang baik, seorang pemuda sedang makan di restoran halal, ia menyuapkan makanannya dengan tangan kanan, seperti yang di anjurkan oleh Rasululloh, "Jika salah seorang dari kalian makan, hendaknya ia makan dengan tangan kanannya, dan jika minum hendaaknya minum dengan tangan kanannya. Karena setan makan dan minum dengan tangan kirinya". (HR. Muslim).

Gambar 19 Muthia saat makan dengan tangan kanan 


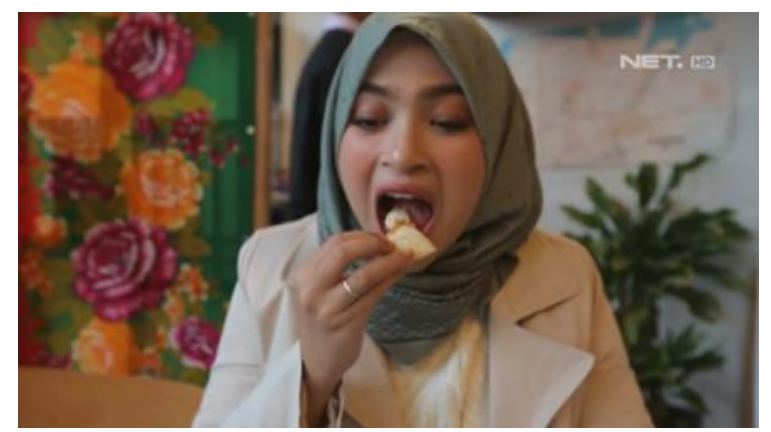

Pesan dakwah yang terdapat pada gambar di atas menunjukan pesan dakwah kategori akhlak, Muthia menyuapkan makanannya tidak mengunakan tangan kiri, tetapi Muthia menyuapkan makanannya dengan tangan kanannya, membiasakan makan dengan tangan kanan adalah akhlak yang baik, karena jika makan dengan tangan kiri hukumnya makruh, Imam Syafi'i menegaskan bahwa makruh hukumnya makan dan minum dengan tangan kiri ketika tidak dalam keadaan darurat.

\section{PENUTUP}

Dalam video program Muslim Travelers Net Tv Edisi Kota Jeju Korea Selatan mengandung tiga kategori pesan dakwah verbal yaitu pesan dakwah akidah, akhlak dan syari’ah. Pesan akidah mengajak penonton untuk tetap menjaga keimanan dimanapun berada melalui pesan suara dari host maupun dialog antara host dengan narasumber, Pesan dakwah akhlak mengajak dan memberikan contoh beberapa akhlak terhadap sesama muslim maupun non muslim dalam berinteraksi. Pesan dakwah syari'ah memberikan pesan suara mengingatkan untuk melaksanakan syari'at islam di Negara Korea Selatan.

Pesan pesan dakwa non-verbal yang terkandung dalam video program Muslim Travelers Net Tr Edisi Kota Jeju Korea Selatan adalah yaitu pesan dakwah akhlak dan syari'ah. Pesan dakwah akhlak mengajak dan memberikan contoh melalui pesan gambar beberapa akhlak terhadap sesama muslim maupun non muslim dalam berinteraksi dan akhlak terhadap lingkungan sekitar. Pesan dakwah syari'ah memberikan contoh pesan gambar bagaimana seorang muslim saat berada di Negara minoritas tetapi melaksakan melaksanakan ibadah shalat, membaca Al Qu'ran dan yang lainnya.

\section{DAFTAR PUSTAKA}

Anshari, Endang Saifuddin. 1996. Wawasan Islam. Jakarta : Rajawali

Arifin, Anwar. 2011. Dakwah Kontemporer Sebuah Studi Komunikasi. Yogyakarta: Graha Ilmu

Aziz, Moh. Ali. 2009. Ilmu Dakwah. Jakarta : Kencana 
Badjuri, Adi. 2010. Jurnalistik Televisi. Yogyakarta : Graha Ilmu

Dahlan, Abdul Aziz, ed. 1996. Ensiklopedi Hukum Islam. Jakarta : Ichtiar Baru van Hoeve

Hefni, Harjani. 2017. Komunikasi Islam. Jakarta : Kencana

Hidajat, M.S. 2006. Public Speaking dan Teknik Presentasi. Yogyakarta: Graha Ilmu

Ilaihi, Wahyu, Lukman Hakim dkk. 2013. Komunikasi Dakwah. Surabaya : IAIN SA Press

Ilaihi, Wahyu. 2010. Komunikasi Dakwah. Bandung : PT Remaja Rosdakarya

Kementrian Agama RI, Al-Qur"ean dan Terjemah, Solo: Ash-Shadiq, 2014

Mahmud, Ali Abdul Walid. 2004. Akhlak Mulia. Jakarta: Gema Insani

Mu’in, Ta’ib Tahir Abdul. 1997. Ilmu Kalam. Jakarta : Widjaya

Mufid, Sofyan Anwar. 2010. Islam dan ekologi manusia. Bandung : Nuansa

Mulyana, Deddy. 2010. Ilmu Komunikasi Suatu Pengantar. Bandung: Rosda

Munir, Muhammad, Wahyu Ilaihi. 2006. Manajemen Dakwah. Jakarta: Kencana

Munir, Muhammad,Wahyu Ilaihi. 2009. Menejemen Dakwah. Jakarta: Kencana

Nasharuddin. 2015. Akhlak: Ciri Manusia Paripurna. Jakarta: Rajawali Pers

Nata, Abuddin. 2014. Metodologi Studi Islam. Jakarta : Rajawali

Rakmat, Jalaluddin. 2017. Metode penelitian komunikasi. Bandung : Simbiosa Rekatama Media

Soyomukti, Nurani. 2010. Pengantar Ilmu Komunikasi. Yogjakarta : Ar-Ruzz Media

Subroto, Darwanto Sastro. 1994. Produksi Acara Televisi Yogyakarta : Duta Wacana University Press

Sukir, Asmuni. 1983. Dasar-Dasar Strategi Dakwah islam. Suarabaya : Al Ikhlas

Sutrisno, P.C.S. 1993. Pedoman Praktis Penulisan Televisi dan video Jakarta : PT. Grasindo

Syafaq, Hammis dkk. 2014. Pengantar Studi Islam, Surabaya: UIN SA Press

Syalut, Syekh Mahmud. 1994. Akidah dan Syariah Islam. Jakarta : Bumi Aksara

Tasmara, Toto. 1997. Komunikasi Dakwah Jakarta : Gaya Media Pratama

Thoifah, I'anatut. 2015. Manajemen Dakwah: Sejarah dan Konsep. Malang : Madani Press

West, Richard dan Lynn H. Turner. 2008. Pengantar Teori Komunikasi Analisis dan Aplikasi. Jakarta : Salemba Humanka

Widjaja, A.W. 1993. Komunikasi, Komunikasi dan Hubungan Masyarakat. Jakarta: Bumi Akasara 